\title{
AN OVERVIEW OF INNOVATION SOURCES IN SMES
}

\author{
Daiana-Maria Tonț ${ }^{*}$, Mihu-Dan Tonţ \\ Doctoral School of Economics, Faculty of Economic Sciences, University of Oradea, \\ Oradea, Romania \\ Bucharest University of Economic Studies, Bucharest, Romania \\ daiana@daianatont.com \\ dan tont@yahoo.com
}

\begin{abstract}
For SMEs, innovation should be embedded it in the organisational culture in order to enable the creation and integration of the physical and virtual worlds, for an enriched customer experience tailored to their needs. There is a myriad of innovation typologies and levels of analysis present in the literature emanating from many disciplines such as management, psychology, economics, sociology and science (Kristiansen 2012). This article focuses on innovation in order to identify and analyse the types and sources of innovation encountered for SMEs by applying different frameworks and perspectives.
\end{abstract}

Keywords: innovation; model; organisational capabilities; SMEs.

JEL classification: M14.

\section{Introduction}

Radical changes in customer behaviour have occurred in recent years. Engagement from their part can only be gained through the offering of entertainment and interactivity as part of the products of services (Pine and Gilmore, 1998). All industries rely on social and technological progress to retain its customers (Ho and Mallick, 2006), with innovation being a key component of capitalising on value creation (Jacobides, Knudsen and Augier, 2006). An SME is defined as small to medium enterprises with less than 250 employees and yearly turnover less than $£ 40$ million (Caputo et al, 2002). SMEs are broadly recognised as global drivers of technological innovation and economic development in both industrialised and developing countries (Kowalski and Pierce 2009). In Europe, SMEs account for 99\% of business, $55 \%$ non-governmental employment and $51 \%$ of turnover (Lee et al, 2010).

\section{Taxonomy of Innovation}

Innovation is imperative in this current and uncertain environment for the survival of an organisation. It provides the organisation with the knowledge for better utilisation of resources, capabilities and technology (Tidd and Bessant, 2011). Innovation is defined as a specific tool used by entrepreneurs to exploit change as an opportunity for different businesses or services (Drucker, 2008), by successfully implementing new processes, products, services and methods to add value in terms of efficiency, effectiveness or quality (O’Sullivan, 2008).

SMEs use innovation as an engine for progress and as a key differentiator from its competitors, exploiting opportunities in order to provide added value for customers and create a competitive advantage in their industry. They develop innovative thinking to solve problems and create new products and services (Selman, 2008). This way, each project is

\footnotetext{
${ }^{*}$ Corresponding author
} 
considered in isolation to maintain a fresh perspective on the challenges and also open to new possibilities.

One innovation typology is navigating between incremental and radical innovation on a system or a component level. They are perceived at the opposite sides of the spectrum, being distinguished by market and technological uncertainty (Drucker, 2008).

Radical innovation embodies new technologies that results in a new market infrastructure, creating demand previously unrecognised by the consumer (Garcia and Calatone, 2002). In order to classify innovation as radical innovation, Kristiansen (2012) emphasised on the reframing of a firm's existing knowledge in new ways by transforming it into significant products and processes. Incremental innovation provides products and services with new features, benefits or improvements to the existing technology in the existing market through the adaptation, refinement and enhancement of the existing products and delivery systems (Garcia and Calatone, 2002). It offers a competitive advantage in a mature market, continuously improving processes for a leaner and more efficient approach (O'Sullivan, 2008).

Another typology is that of the four Ps of innovation: product innovation, process innovation, position innovation and paradigm innovation (Bessant and Tidd, 2011). This provides an overview on four dimensions in which innovation can take place within an organisation.

In order to achieve these kinds of innovation, the organisational capabilities of SMEs have to continuously adapt and be extremely flexible when introducing new component, system or architectural level innovation (Henderson and Clark, 1990). Architectural innovation is used to change the way components of a product are linked together into new patterns to achieve higher performance while leaving the core design concepts untouched (Henderson and Clark, 1990; Bessant and Tidd, 2011). Whereas a component innovation is changing the core design concept, which performs a well-defined function, while the links between them remain the same (Henderson and Clark, 1990). System innovation refers to a group of elements working together in different units on different aspects of the problem by using scientific and technological knowledge (Garcia and Calatone, 2002).

SMEs should use architectural, system and component innovation for their projects in order to exploit, explore, reframe and co-evolve in the innovation space. This helps to increase and extend the value through core and peripheral offerings to their customers (Bessant and Tidd, 2011).

From the market's perspective, the level of innovation of new products or services can be categorised as continuous or discontinuous. Continuous innovation provides with new features, benefits or improvements to the existing market, whereas discontinuous innovation embodies a new technology that results in new market infrastructure (Gammoh, Voss and Skiver, 2011).

SMEs are an organic and dynamic system, with clear strategic leadership and direction, committing resources to fully satisfy customer needs and requirements (Bessant and Tidd, 2011). Customers provide with critical insight, which the bank uses to continuously improve and innovate products and services. This allows SMEs to capture emergent needs and opportunities to successfully manage growth. Knowledge throughout the organisation is flexibly shared according to the requirements of the project for a more feasible and effective resource deployment (Pujol and Droege, 2011).

In order to be successfully implemented, SMEs' internal and external resources are efficiently and effectively integrated to harness the potential of each innovation in a way that creates value for customers.

Sources of Innovation

SMEs utilise ideas and knowledge from a variety of internal and external sources to enhance the possibility for producing more tailored innovation for its customers. Customers 
are the core elements for innovative thinking. Their knowledge and experience help shape new products and services and offer insights that fuel innovation (Drucker, 2008).

The in depth analysis of the customer trends, needs and expectations, provided the starting point for each innovation (Pujol and Droege, 2011). Technology has enabled the mechanisation of the customer knowledge using tools to get to know the customer better. This has helped in optimising opportunities into products and raising the standards in any industry through a better utilisation of resources.

Customers are used as innovators to add value and increase the flexibility of the processes (Trompke and Hippel, 2002) by creating and developing relationships on a personal level through continuously involving them along the innovation process (Pine and Gilmore, 2011). This further developed the products and services to fully satisfy the customer needs accordingly, co-creating and adding value along the way (Oke, 2007).

\section{Innovation models in SMEs}

Open innovation is an external method of gathering new knowledge to accelerate and make the innovation process more efficient and effective in resource deployment (Chesbrough, 2006). SMEs should use mostly strategic partnership to incorporate external thinking into the strategic planning process, insights coming from a collaborative inquiry of all the points of view involved for a wider overview of the identified problem. These alliances provide SMEs with additional knowledge, improving the quality and the value of the products and services through co-creation. Open innovation can lead to networking opportunities: by participating at fairs and sponsoring idea competitions and innovation blogs, SMEs remaining receptive to external talent (Pujol and Droege, 2011).

Other sources of innovation include knowledge push, need pull and recombinant innovation. Knowledge push is developed from technological progress, whereas need pull is satisfying an opportunity triggered by a social or market need (Bessant and Tidd, 2011). Recombinant innovation refers to ideas in one industry transferred to a new context (Bessant and Tidd, 2011).

Innovation is identified as the main driver for companies to prosper, grow and sustain high profitability (Drucker, 2004). Internal R\&D is not considered as an invaluable strategic asset in new ideas generation, companies recently moving their focus on combining internal and external innovation to create business value (Chesbrough, 2006). Also, changes in society and industry have reshaped the boundaries of the innovation process, increasing the mobility of knowledge throughout industries (Elmquist, Fredberg and Ollila, 2009). Chesbrough (2006) has identified four major reasons for these changes, which include the increase mobility of skilled workers, expansion of venture capital, external options for unused technology and the increase availability of highly capable outsourcing partners.

These changes have challenged and shifted the focus from the old model of innovation, closed innovation to open innovation, making organisations more aware of external ideas, technologies and opportunities (Inauen and Schenker-Wicki, 2012). Closed innovation meant having full control over the innovation process and intellectual property (Chesbrough, 2006). This was a classical technology push model as an in-house exploitation of the sufficiently funded R\&D, which generated mostly incremental innovation by building on the organisation's core competencies, products and services (Inauen and Schenker-Wicki, 2012). On the other hand, open innovation also offers more chances for radical innovation by taking advantage of the mobility of knowledge and technology, diversifying competencies along the process (Chesbrough, 2006). Table 1 presents a short comparison between closed and open innovation. 
Table 1: Closed vs. Open Innovation

\begin{tabular}{|c|c|}
\hline Closed innovation & Open innovation \\
\hline $\begin{array}{l}\text { Structured framework to developing } \\
\text { internal innovation (Bessant and Tidd, } \\
2011 \text { ); } \\
\text { Rigid approach (Ulhoi, 2004); } \\
\text { Strong R\&D investment represented a } \\
\text { barrier for potential entrants } \\
\text { (Chesbrough, 2006); } \\
\text { Monopolistic overview (Rahman and } \\
\text { Ramos, 2010); } \\
\text { Very successful approach to retaining } \\
\text { and sustaining competitive advantage } \\
\text { in the past (Drucker, 2007); }\end{array}$ & $\begin{array}{l}\text { Open framework focused on increasing } \\
\text { collaboration to accelerate the } \\
\text { process (Bessant and Tidd, 2011); } \\
\text { Flexible approach (Ulhoi, 2004); } \\
\text { Access to new knowledge (Chesbrough, 2006); } \\
\text { Reducing R\&D and commercialisation costs } \\
\text { Rahman and Ramos, 2010); } \\
\text { Involving customers into the development and } \\
\text { commercialisation process co-creating } \\
\text { products (Ulhoi, 2004); } \\
\text { Fostering a learning culture within the } \\
\text { organisation (Drucker, 2007); } \\
\text { Stimulates networking between employees of } \\
\text { different organisation (Chesbrough, 2006). }\end{array}$ \\
\hline
\end{tabular}

Open innovation shifts focus from the internal innovation process to the search and exploration for novel knowledge and exploiting it (Inauen and Schenker-Wicki, 2012). It is defined as leveraging external and internal sources of technology, knowledge and innovation to drive growth, presenting lower risks and speeding up the research and innovation process by connecting the organisation with a collaborative partner that has already developed the technology or who is further along on the development path (Chesbrough, 2006). Organisations tend to be more flexible and adaptable in the innovation process, creating a link between the external environment and the internal R\&D processes in the search for new ideas that have potential (Elmquist, Fredberg and Ollila, 2009). Altogether, open innovation can help in improving the performance of the organisation by harnessing and maximising the innovation outcome, offering new knowledge insights and a collaborative network for creating and sustaining competitive advantage (Inauen and Schenker-Wicki, 2012).

There are two types of open innovation: outside-in (or technology exploration) and insideout (or technology exploitation). Outside-in focuses on searching and adopting new ideas and technology from outside the organisation whereas inside-out is concerned with how innovation can be commercialised through external assistance (Inauen and SchenkerWicki, 2012). External collaboration in both cases can help foster and increase creativity and the efficiency of the innovation process for a more competitive edge, re-shaping the industry standards (Bogers, 2011). Most organisations combine both types to exploit and explore the current internal and external environment in order to create the greatest value possible from their competencies and capabilities (Rahman and Ramos, 2010).

Open innovation is an organic and interactive process that takes advantage of the technological development and the global availability of knowledge (Inauen and SchenkerWicki, 2012). By doing this, organisation reduce costs for R\&D, establishing new sources of funding other research (Chesbrough, 2006). Communication is also improved, actively and regularly involving stakeholders, lead users and external collaborators to understand the unmet needs and provide a suitable innovative solution (Bogers, 2011). The outside partners are seen as peers or as co-development partners, sharing the risks and transferring knowledge in its efforts to create a suitable solution for the problems identified by the organisation (Inauen and Schenker-Wicki, 2012). By using open innovation, the innovation process is accelerated, introducing more innovative ideas and reducing time to market (Sloane, 2011). 
The main disadvantage for using open innovation consist of reinventing organisational procedure and structure to create the right mechanism and support system to help protect the intellectual property and the competitive advantages created (Elmquist, Fredberg and Ollila, 2009). Also, the successful identification and integration of the internal and external knowledge require specific skills, procedures and frameworks to harness the full potential of the innovation process (Sloane, 2011). However, many issues are concerning tacit and explicit knowledge and technology transfer. Protecting and managing effectively intellectual property reduces the changes of imitation or 'me-too' strategies in the industries, allowing the organisation to retain its competitive edge and value gained from the first mover strategy (Bogers, 2011). Open innovation does present more complex challenges than closed innovation but if the organisation has a clear vision, direction, flexibility and adaptability it will surely understand and evaluate the external environment properly creating products and services for unmet needs but also contingency strategies to minimise risks (Antikainen, Makipaa and Ahonen, 2010).

Open innovation is typical for large organisations, which have more capabilities and financial resources than SMEs; but intense competition has forced SMEs to increasingly adapt open innovation as a measure of enhancing performance and to strengthen their competitive position in the industry (Rahman and Ramos, 2010). However, as more and more SMEs adopt it as part of their corporate strategy, developing a competitive edge to create and sustain competitive advantage becomes essential. Exploring different external sources that can help SMEs overcome certain weaknesses such as limited resources or knowledge and lack of commitment to R\&D or technological competencies (Lee, Hwang and Choi, 2012).

Thus, it is encourages stimulating economic development at a local, regional or even national level (Rahman and Ramos, 2010). In order to innovate, SMEs have to overcome certain limitations, which can be found in Table 2.

Table 2: Problems and solutions in SMEs in the innovation process

\begin{tabular}{|c|c|}
\hline Problems & Solutions \\
\hline $\begin{array}{l}\text { High costs and high risks (Caputo et al, } \\
\text { 2002); } \\
\text { Fear; Moderate knowledge base (Wang, } \\
\text { Wang and Horng, 2010); } \\
\text { Depth of experience (Lee, Hwang and } \\
\text { Choi, 2012); } \\
\text { Knowledge absorptive capacity (Wang, } \\
\text { Wang and Horng, 2010); } \\
\text { Modest financial resources (van de Vrade } \\
\text { et al, 2008); } \\
\text { Lack of adequate organisational structure } \\
\text { (Lee, Hwang and Choi, 2012); }\end{array}$ & $\begin{array}{l}\text { Networked architecture by increasing } \\
\text { interaction (Lee, Hwang and Choi, 2012); } \\
\text { Carrying out an innovation audit (van de } \\
\text { Vrade et al, 2008); } \\
\text { Investigating potential obstacles to } \\
\text { innovation transfer (van de Vrade et al, } \\
\text { 2008); } \\
\text { Participating in niche industries (Caputo et } \\
\text { al, 2002); } \\
\text { External transfer of innovation (Lee, } \\
\text { Hwang and Choi, 2012). }\end{array}$ \\
\hline
\end{tabular}

As pointed out in Table 2, SMEs do not have sufficient capacity to manage the whole innovation process by themselves. The external complexity and uncertainty of the environment have forced these types of SMEs to open up their innovation process, encouraging them to collaborate with other firms through networking, collaboration and alliances (Lee et al, 2010) (Figure 1 and Figure 2). Large organisations are increasingly interested in collaborative innovation partnerships as SMEs have strong competences and expertise that can accelerate the product or service development process (Chessbrough, 2006). Finding a suitable partner often uses an intermediary in making a more efficient and effective collaborative network for a more open structure (Ulhoi, 2004). As pointed out in 
Table 2, SMEs do not have sufficient capacity to manage the whole innovation process by themselves.

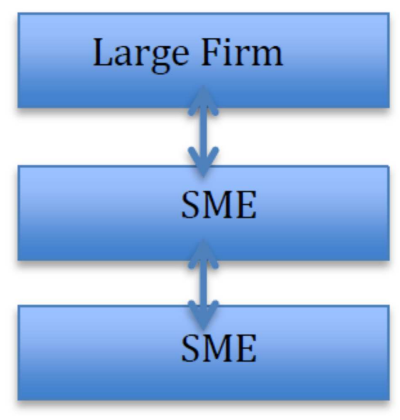

Figure 1: Possible model for open innovation SMEs -Outside-in Source: Lee et al, 2010

SMEs concentrate on retaining high levels of internal competence because of the fear of giving away their technology to competitors (Lee et al., 2010).

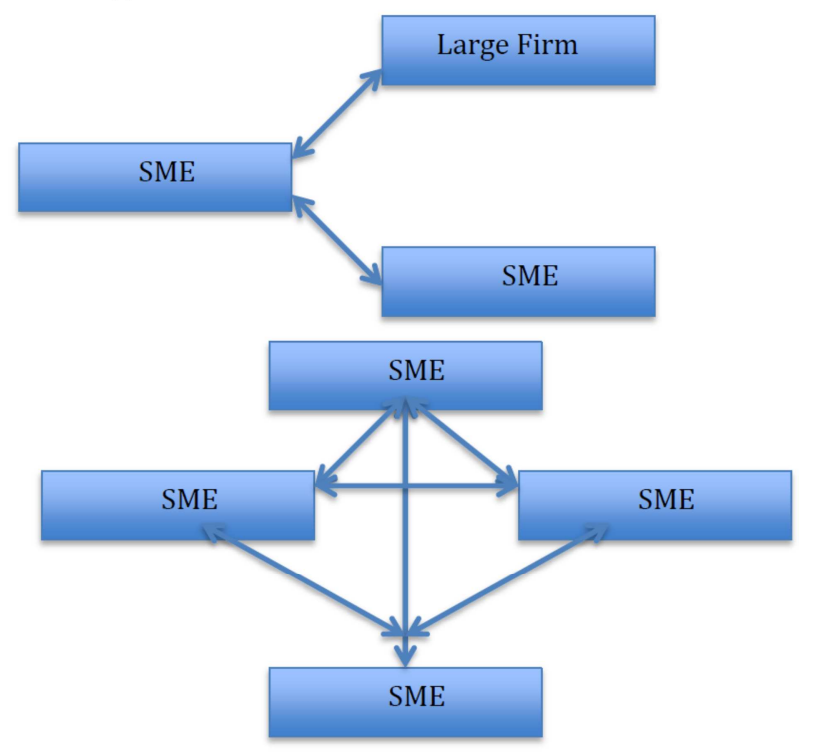

Figure 2: Possible models for open innovation-Inside-out model for SMEs Source: Lee et al, 2010

These models are based on outsourcing agreements or strategic alliances with other SMES (Lee et al, 2010).

The adoption of the models stated above depends on which type of organisation the SME is: service or manufacturing. Traditionally, closed innovation was present in the SMEs that operate in the manufacturing sector in order to retain control whereas in the service industry, SMEs are more inclined to use collaborative networks in the innovation process (Lee, Hwang and Choi, 2012). Also, SMEs use different open innovation models in the private and public sector. In the private sector, there is much more reliance on new product development to increase revenues and achieve competitive advantage while in the public 
sector, open innovation is focused on improving service performance and adding value through a process of continuous interaction among stakeholders (Lee, Hwang and Choi, 2012).

The sources for SMEs competitive advantage consist of protecting and leveraging their intellectual property in the open innovation process (Huizingh, 2010). This is considered a challenge in managing open innovation; SMEs require more intellectual property management for a win-win exchange in the open global marketplace for innovation (Gassman, Enkel, Chesbrough, 2010). Another requirement would be implementing a proactive strategy to foster a culture of open innovation for internal and external collaboration and converging different organisation structures into a synergistic collaboration (Hartman and Renold, 2010). In this global knowledge economy of the $21^{\text {st }}$ century, these risks are manageable and the potential rewards can be enormous (Kowalski and Pierce, 2009).

Proactive linkages for SMEs are created through the internal and external exploitation of human capital in order to harness the power of acquiring knowledge and information (Wang, Wang and Horng, 2010). This is heavily relied on as it reduces environmental uncertainties and helps in assimilating a larger amount of knowledge for the creation of a networked architecture for open innovation (Lee, Hwang and Choi, 2012). The vast amount of information is monitored through the use of diversified external sources such as stakeholders input throughout the value chain, market research and customer contact (especially lead users) for an efficient utilisation of resources in the emerging global knowledge economy (Wang, Wang and Horng, 2010). This sourcing of knowledge will consolidate R\&D, connecting, developing and integrating into global innovation networks (Bessant and Tidd, 2011).

\section{Conclusions}

New challenges are faced by SMEs in order to compete on the market with innovative products or services. Thus, they have to resource to innovation in order to look for new sources of technology and innovation among global research and innovation community to reach beyond a specific industry (Inauen and Schenker-Wicki, 2012).

By understanding the external environment, SMEs can seize opportunities in the market place. SMEs continually realigns and integrates its internal and external resources in order to innovate with the customer's understanding and requirements for a more flexible, transparent and adaptable organisational structure. Innovation is systematically used to respond more rapidly and effectively to the changing needs of customers. This is done by exceeding expectations by providing customers with more personalised, functional and innovative products and services while increasing the value provided.

All in all, keeping an external focus is crucial for identifying opportunities in this uncertain environment. This will bring a new insight of the untapped needs on the market, innovation being essential to ensure a competitive stance in the industry.

SMEs need to consider their capacities and capabilities to compete and grow in the marketplace, having enormous potential for open innovation as it harnesses the internal and external knowledge and technology available creating a collaborative network for innovation. This may not be the perfect solution for every SME but if the organisation is committed to innovation it should experiment with it as realigns and integrates internal and external knowledge and technology for a more flexible and rapid response on the market.

\section{References}

Adams, K. (2005). The sources of innovation and creativity [Online] Available from http://www.fpspi.org/Pdf/InnovCreativity.pdf, [10 Feb 2016]. 
Antikainn, M., Makipaa, M. and Ahonen, M. (2010). 'Motivating \& supporting collaboration in open innovation'. European Journal of Innovation Management, vol. 13, no. 1, pp. 100119, [Online]. Available: http://dx.doi.org/10.1108/14601061011013258, [10 Feb 2016].

Bessant, J. and Tidd, J. (2011). Innovation and entrepreneurship, $2^{\text {nd }}$ edition, Chichester: John Wiley \& Sons.

Bogers, M. (2011). 'The open innovation paradox: knowledge sharing \& protection in R\&D collaborations'. European Journal of Innovation Management, vol. 14, no. 1, pp. 93-117.

Caputo, A., Cucchiella, F., Fratocchi, L., Pelagagge, P. and Scacchia, F. (2002). 'A methodological framework for innovation transfer to SMEs'. Industrial Management \& Data Systems, vol. 102, no. 5, pp. 271-283.

Chesbrough, H. (2006). 'Open innovation: A new paradigm for understanding innovation' [Online]. Available: http://www.emotools.es/static/upload/files/Openinnovationparadigm.pdf Coccia, M. (2006). Classification of innovations survey \& future directions [Online]. Available: http://www.ceris.cnr.it/ceris/workingpaper/2006/WP 206 COCCIA NEW.pdf, [04 Feb 2016].

De Vrande, V., de Jong, J., Vanhaverbeke, W. and de Rochemont, M. (2008). Open innovation in SMEs: Trends, motives \& management challenges [Online]. Available: http://www.insme.org/files/3388, [05 Feb 2016].

Drucker, P. (2007). Innovation and entrepreneurship, $2^{\text {nd }}$ edition, Oxford: ButterworthHeinemann.

Drucker, P. (1985). Innovation \& Entrepreneurship. Practice \& Principles, New York: Harper \& Row.

Elmquist, M., Fredberg, T. and Ollila, S. (2009). 'Exploring the field of open innovation'. European Journal of Innovation Management, vol. 12, no. 3, pp. 326-345.

Gammoh, B., Voss, K. and Skiver, R. (2011). 'Consumer evaluation of continuous \& discontinuous innovation'. American Journal of Business, vol. 26, no. 1, pp. 65-79, [Online]. Available: http://dx.doi.org/10.1108/19355181111124115, [02 Feb 2016].

Garcia, R. and Calatone, R. (2002). 'A critical look at technological innovation typology \& innovativeness terminology'. Journal of Product Innovation Management, vol. 19, no. 1, pp. 110-132, [Online]. Available: http://www.creativante.com.br/download/inovatividade.pdf, [13 Feb 2016].

Gassmann, O, Enkel, E. and Chesbrough, H. (2010). The future of open innovation [Online]. Available: $\quad$ http://onlinelibrary.wiley.com/doi/10.1111/j.14679310.2010.00605.x/full, [11 Feb 2016].

Hartman, D. and Renold, E. (2010). Open innovation in SMEs [Online]. Available: http://pure.Itu.se/portal/files/36592601/j.1540 627X.2012.00354.x.pdf, [03 Feb 2016].

Henderson, R. \& Clark, K. (1990). 'Architectural Innovation: The reconfiguration of existing product technologies \& the failure of established firms', Administrative Science Quarterly, vol. 35 , no. 1 , pp. 9-30.

Ho, S. and Mallick, S. (2006). The impact of Information Technology on the banking industry [Online]. Available: http://webspace.qmul.ac.uk/pmartins/mallick.pdf, [01 Feb 2016].

Huizingh, E. (2010) Open innovation: State of the art \& future perspective [Online]. Available: http://www.sciencedirect.com/science/article/pii/S0166497210001100, [01 Feb 2016].

Humphreys, P., McAdam, R. and Leckey, J. (2005). 'Longitudinal evaluation of innovation implementation in SMEs' European Journal of Innovation Management, vol. 8, no. 3, pp. 283-304, [Online]. Available: http://dx.doi.org/10.1108/14601060510610162, [02 Feb 2016].

Inauen, M. and Schenker-Wicki, A. (2011). 'The impact of outside-in open innovation on innovation performance'. European Journal of Innovation Management, vol. 14, no. 4, pp. 
496-520, [Online]. Available: http://dx.doi.org/10.1108/14601061111174934, [03 Feb 2016].

Inauen, M. and Schenker-Wicki, A. (2012). 'Fostering radical innovations with open innovation'. European Journal of Innovation Management, vol. 15, no. 2, pp. 212-231.

Jacobides, M., Knudsen, T. and Augier, M. (2006). Benefiting from innovation: Value creation, value appropriation \& the role of industry architectures [Online]. Available: http://www.dimeeu.org/files/active/0/JacobidesPAPER1.pdf, [12 Feb 2016].

Kristiansen, J. (2012). An update on the radical innovation management family [Online]. Available: http://druid8.sit.aau.dk/acc papers/k289xrdnkgxlad1feeiet227x2xp.pdf, [10 Feb 2016].

Kowalski, S. and Pierce, F. (2008). SMEs, Open Innovation \& IP Management: Advancing Global Development [Online]. Available: http://www.wipo.int/edocs/mdocs/sme/en/wipo smes rom 09/wipo smes rom 09 b the me02 2-related1.pdf, [01 Feb 2016].

Lee, S., Park, G., Yoon, B. and Park, J (2010). 'Open innovation in SMEs- An intermediated network', Research Policy, vol. 39, no. 3, pp. 290-300, [Online]. Available: http://www.sciencedirect.com/science/article/pii/S0048733309002248, [01 Feb 2016].

Lee, S., Hwang, T. and Choi, D. (2012). 'Open innovation in the public sector of leading countries'. Management Decision, vol. 50, no. 1, pp. 147-162, [Online]. Available: http://dx.doi.org/10.1108/00251741211194921, [19 Nov 2015].

MacVaugh, J. and Schiavone, F. (2010). 'Limits to the diffusion of innovation'. European Journal of Innovation Management, vol. 13, no. 2, pp. 197-221, [Online]. Available: http://dx.doi.org/10.1108/14601061011040258, [10 Dec 2015].

Muller, A., Hutchins, N. and Cardoso Pinto, M. (2012). 'Applying open innovation where your company needs it most'. Strategy \& Leadership, vol. 40, no. 2, pp. 35-42, [Online]. Available: http://dx.doi.org/10.1108/10878571211209332, [09 Feb 2016].

Oke, A., Burke, G. and Myers, A. (2007). 'Innovation types \& performance in growing UK SMEs'. International Journal of Operations \& Production Management, vol. 27, no. 7, pp. 735-753, [Online]. Available: http://dx.doi.org/10.1108/01443570710756974, [19 Jan 2016]. Molander, J. (2010). How can banks use social media \& mobile apps [Online]. Available: http://econsultancy.com/uk/blog/5619-how-banks-can-use-social-media- \&-mobile-apps, [17 Jan 2016].

O'Sullivan (2008). Innovation [Online]. Available: http://www.sagepub.com/upmdata/23137 Chapter 1.pdf $\left[27^{\text {th }}\right.$ March 2012].

Oke, A. (2007). 'Innovation types \& innovation management practices in service companies'. International Journal of Operations \& Production Management, vol. 27, no. 6, pp. 564-587, [Online]. Available: http://dx.doi.org/10.1108/01443570710750268, [10 Feb 2016].

Pine, B. and Gilmore, J (1998). 'Welcome to the experience economy'. Harvard Business Review, July-August, pp. 97-105.

Pinho, J. (2008). 'TQM \& performance in small medium enterprises: The mediating effect of customer orientation \& innovation'. International Journal of Quality \& Reliability Management, vol. 25, no. 3, pp. 256-275.

Rahman, H. and Ramos, I. (2010). 'Open Innovation in SMEs: From closed boundaries to networked paradigm'. Issues in Informing Science \& Information Technology, vol 7, no. 2, pp. 470-487.

Read, A. (2000). 'Determinants of successful organisational innovation'. Journal of Management Practice, vol. 3, no. 1, pp. 95-119.

Read, S. and Robertson, D. (2009). 'Implementing an open innovation strategy: lessons from Napoleon'. Strategic Direction, vol. 25, no. 6, pp. 3-5.

Selman (2008). Leadership \& Innovation: relating to circumstances and change [Online]. Available: http://www.innovation.cc/discussion-papers/selman.pdf, [29 Jan 2016]. 
Sloane, P. (2011). 'The brave new world of open innovation', Strategic Direction, vol. 27, no. 5, pp. 3-4.

Slowinski, G. and Sagal, M. (2010). 'Good practices in open innovation'. Technology management, vol. 16, no. 6, pp. 38-45 [Online]. Available: http://www.strategicalliance.com/articles/good practice article.pdf, [10 Dec 2015].

Stage-Gate (2012). Roadmap for new product development [Online]. Available: http://www.prod-dev.com/stage-gate.php, [12 Feb 2016].

Teten Advisors (2010). Peter Drucker on the seven sources of systematic innovation [Online]. Available: http://www.teten.com/blog/2010/01/13/peter-drucker-on-the-sevensources-of-systematic-innovation-2l, [16 Feb 2016].

Ulhoi, J. (2004). 'Open source development: a hybrid in innovation \& management theory'. Management Decision, vol. 42, no. 9, pp. 1095-1114, [Online]. Available: http://dx.doi.org/10.1108/00251740410565145, [12 Feb 2016].

Von Hippel, E. (1988). The sources of Innovation [Online]. Available: http://web.mit.edu/evhippel/www/books/sources/Sofl.pdf, [10 Feb 2016].

Vujovic, S. and Ulhoi, J. (2008). 'Online innovation: the case of open source software development'. European Journal of Innovation Management, vol. 11, no. 1, pp. 142-156.

Wang, Y., Wang, Y. and Horng, R. (2010). 'Learning \& innovation in small \& medium enterprises'. Industrial Management \& Data Systems, vol. 110, no. 2, pp. 175-192.

White, J., Gorton, M. and Chaston, I. (1993). 'Facilitating co-operative networks of hightechnology small firms: problems \& strategies'. Journal of Small Business \& Enterprise Development, vol. 3, no. 4, pp. 34-47.

\section{Bio-note}

Daiana Tonț is a current Ph.D. student in Economics. Prior to this programme, Daiana has studied Bachelor of Arts with Honours in Business and Management at the University of the Highlands and Islands in Scotland followed by Master of Science in Economics and Marketing at Erasmus University Rotterdam in the Netherlands. Her research interests focus on consumer behaviour in an offline and online environment as well as sources of innovation in SMEs. From a work experience point of view, Daiana is currently an Operations Graduate in the Food and Beverage industry. 